\title{
Positioning Error Compensation of a Flexible Track Hybrid Robot for Aircraft Assembly Based on Response Surface Methodology and Experimental Study
}

\section{Zhihao Li}

Nanjing University of Aeronautics and Astronautics

Wei Tian ( $\nabla$ tw_nj@nuaa.edu.cn )

Nanjing University of Aeronautics and Astronautics

Min Wang

Nanjing University of Aeronautics and Astronautics

Bo Li

Nanjing University of Aeronautics and Astronautics

Wenhe Liao

Nanjing University of Aeronautics and Astronautics

\section{Research Article}

Keywords: Aircraft assembly, Flex track hybrid robot, Error compensation, Response surface methodology, Robotic drilling

Posted Date: July 6th, 2021

DOI: https://doi.org/10.21203/rs.3.rs-656240/v1

License: (c) (i) This work is licensed under a Creative Commons Attribution 4.0 International License. Read Full License

Version of Record: A version of this preprint was published at The International Journal of Advanced Manufacturing Technology on November 11th, 2021. See the published version at https://doi.org/10.1007/s00170-021-08134-8. 


\title{
Positioning error compensation of a flexible track hybrid robot for aircraft assembly based on response surface methodology and experimental study
}

\author{
Zhihao Li, Wei Tian, Min Wang, Bo Li, Wenhe Liao \\ College of mechanical and electrical engineering, Nanjing University of Aeronautics and Astronautics, \\ Nanjing 210016 \\ *Corresponding author: Wei Tian (E-mail: tw_nj@nuaa.edu.cn), Zhihao Li (E-mail:hao_36@163.com)
}

\begin{abstract}
:
With the development of aviation industry, more stringent demands are put forward for the performance and manufacturing level of aircraft. Moreover, the automation and precision of aircraft assembly determine the efficiency and quality of aircraft production. In order to improve the positioning precision of the flexible track hybrid robots which are applied to the flexible automatic assembly of aircraft, a precision compensation method based on response surface methodology was proposed in this paper. Firstly, the global positioning error model, optimized by characteristics of error data, was constructed to predict the positioning errors of the flexible track hybrid robot- Secondly, the predicted errors are utilized to realize the compensation of the target points at drilling workspace on nose and front fuselage assembly areas. Finally, a series of experiments of the flexible track hybrid robot with no-load and drilling scenarios are implemented to validate the proposed precision compensation method. The experiment of a hybrid robot for aircraft assembly shows that the mean value of the absolute positioning precision of the end-effector was promoted from $0.081 \mathrm{~mm}$ to 0.025 $\mathrm{mm}$, maximum error reduced from $0.143 \mathrm{~mm}$ to $0.039 \mathrm{~mm}$., respectively, which means that the position accuracy of the robot is increased by $69.1 \%$ and $72.7 \%$ for two experimental conditions.
\end{abstract}

Keywords: Aircraft assembly; Flex track hybrid robot; Error compensation; Response surface methodology; Robotic drilling 


\section{Introduction}

In the process of aircraft manufacturing, the application of various robots has improved the production efficiency, automation level and quality reliability of aircraft automatic assembly. In the process of automatic drilling and riveting with robot as carrier and end-effector, the requirements of precise positioning precision must be met first, otherwise the assembly quality of the aircraft will be seriously restricted[1]. Therefore, improving the positioning precision of robot and end-effector is the key measure to achieve high precision hole making process quality.

In order to improve the positioning precision of the robot, there are two main methods[2] for robot precision compensation: one is to add terminal feedback detection to achieve full closed-loop control; The other method is to improve the absolute positioning precision of the robot by off-line calibration.

The method of compensating positioning precision by adding terminal feedback detection is the most general, convenient and stable way, and the feasibility is good. In this method, the robot, sensor and control system are integrated by adding on-line measurement sensor, and the closed-loop real-time feedback compensation is formed[3]. However, for some complex non-standard and hybrid robots, it is difficult to arrange the online detection device and realize the online detection and real-time compensation of positioning error due to the narrow layout space[4], the constraints of design quality and the closing of its own structure.

The error compensation method based on high precision robot calibration first requires the establishment of a complex robot kinematics model[5], and uses advanced and precise measuring instruments and mature parameter identification methods to identify geometric parameters, so that the identified parameters can correct the kinematics model of the robot control system. This method requires very high precision of kinematics parameter identification, and it is difficult to quantify the influence of non-geometric parameters of the robot[6]. The inverse calibration method based on neural network[7] is to obtain the accurate joint coordinates of each joint of the robot through the calculation of neural network under the premise of the expected position and pose in the world coordinate system. Although this method can compensate the error, it needs to solve the complex inverse kinematics, which has a large amount of computation and poor responsiveness[8].

The factors that affect the positioning precision of the end-effector of the robot include but are not limited to the straightness of the guide rail[9], screw pitch error[10], ambient temperature and 
lubrication conditions[11], etc. Therefore, the precision compensation method is more complicated. At present, the precision compensation methods for end-effector are generally divided into two kinds[12], one is the internal parameter error modeling method of the drive shaft, the other is the empirical interpolation method. The internal parameter error modeling method of the drive shaft needs to calculate the error models of the straightness of the guide rail and the screw pitch[16], which will involve the identification of internal parameters such as the ball stiffness of the sliders of the linear guide rail on both sides, the torsional stiffness of the screw and the screw pitch. Therefore, the precision of the identification parameters determines the precision of the error model[17], which puts forward strict requirements for parameter identification, which is difficult to calculate and difficult to evaluate the identification precision. The principle of empirical interpolation method is to detect the actual position reached by the system during the execution of the target instruction through high-precision measuring tools, calculate the positioning error of the terminal in the whole trip, and write the positioning error data into the numerical control program[18]. During the execution of the target instruction, the interpolation compensation can be carried out automatically by looking up the table. Although this method is simple in real time, quick in response and does not require any operation, it does not establish error model for the whole trip and cannot predict the positioning error of any point. If this method wants to improve the interpolation compensation precision, it needs to increase the number of samples as much as possible, and the workload is heavy[22]. It is difficult to find an accurate and universal error model and compensation method because of the structure complexity and difference of different control systems, the influence factors of complex and alternating positioning error of CNC equipment and the different application scenarios[23].

According to the above problem, this paper proposes a position precision compensation method of hybrid robot with end-effector based on response surface, this method through the actuators work schedule at the end of the sampling and analysis of positioning error data, fitting out global positioning error response surface, predicted the end of the actuator working travel all targets within expectations point positioning error, the target coordinates error compensation to the theory of instruction, so as to realize the ascension of positioning precision. This method has the advantages of small amount of computation, quick responsiveness, wide versatility and good applicability. 


\section{Precision analysis and error modeling}

\subsection{Requirements of aircraft assembly}

In the whole process of aircraft manufacturing, the workload of component and fuselage assembly occupies the absolute proportion of the whole production process. There are two main reasons for this situation: one is the characteristics of aircraft assembly process, the other is the requirements of aircraft assembly process.

The craft of aircraft assembly mainly has two obvious characteristics. First, the connection technology involved in aircraft assembly is large in variety and number. Most of the connecting methods of aircraft are riveting, screw joint and glue, etc. These connecting technologies themselves have the characteristics of large deformation and difficult to control the precision of the connection. The shape and size of aircraft structure are determined by the assembly process, so the accuracy of assembly technology directly determines the assembly quality of aircraft. Second, the aircraft assembly process uses a large number of complex and non-general tooling, fixture. The aircraft has complex shape, large size and poor rigidity. In the assembly process, a large number of auxiliary tooling and fixtures must be used to fix the position of the parts and control the deformation of binding fittings to ensure the accuracy of assembly.

The requirements of aircraft assembly technology also directly affect the process of aircraft manufacturing. Aircraft assembly has two main stringent requirements. The first is the strength of aircraft connection area. In the whole process of aircraft assembly, the first requirement of aircraft assembly quality is to meet the strength of any joint surface. No matter what kind of connection is adopted, a slight deviation in technological quality will cause serious defects of the whole aircraft, and even lead to serious accidents. The second, the accuracy of the aircraft connection is required. Aircraft skin, frame and purlin must be connected in such a way as to ensure accuracy. On the outer surface of aircraft, if the rivets protrude too high or submerge too low of the countersunk socket, which not only affects aerodynamic layout of the aircraft, but also causes uneven stress in riveted area, and even causes the skin tearing in serious cases.

The assembly and technological process of aircraft nose and front fuselage are shown in Fig 1.The aircraft nose and the front fuselage are accurately connected by auxiliary tooling. The ribband is 
mounted across the joint area, connecting the nose and the front fuselage. The auxiliary fasteners are used to tighten aircraft skin and ribband. According to technical requirements of assembly process, precise drilling, countersink and deburring are carried out along both sides of the joint ring seam. Then aircraft skin and ribband are riveted together to finally realize the assembly of aircraft nose and the front fuselage.

According to the aircraft assembly process requirements and assembly process, it is the first step to ensure the drilling quality of the fuselage skin to realize the fuselage assembly. It's also a crucial step. The quality of drilling in the joint area of aircraft fuselage determines the quality of riveting, thus the quality of fuselage assembly, and then the manufacturing level, quality and service life of aircraft. 


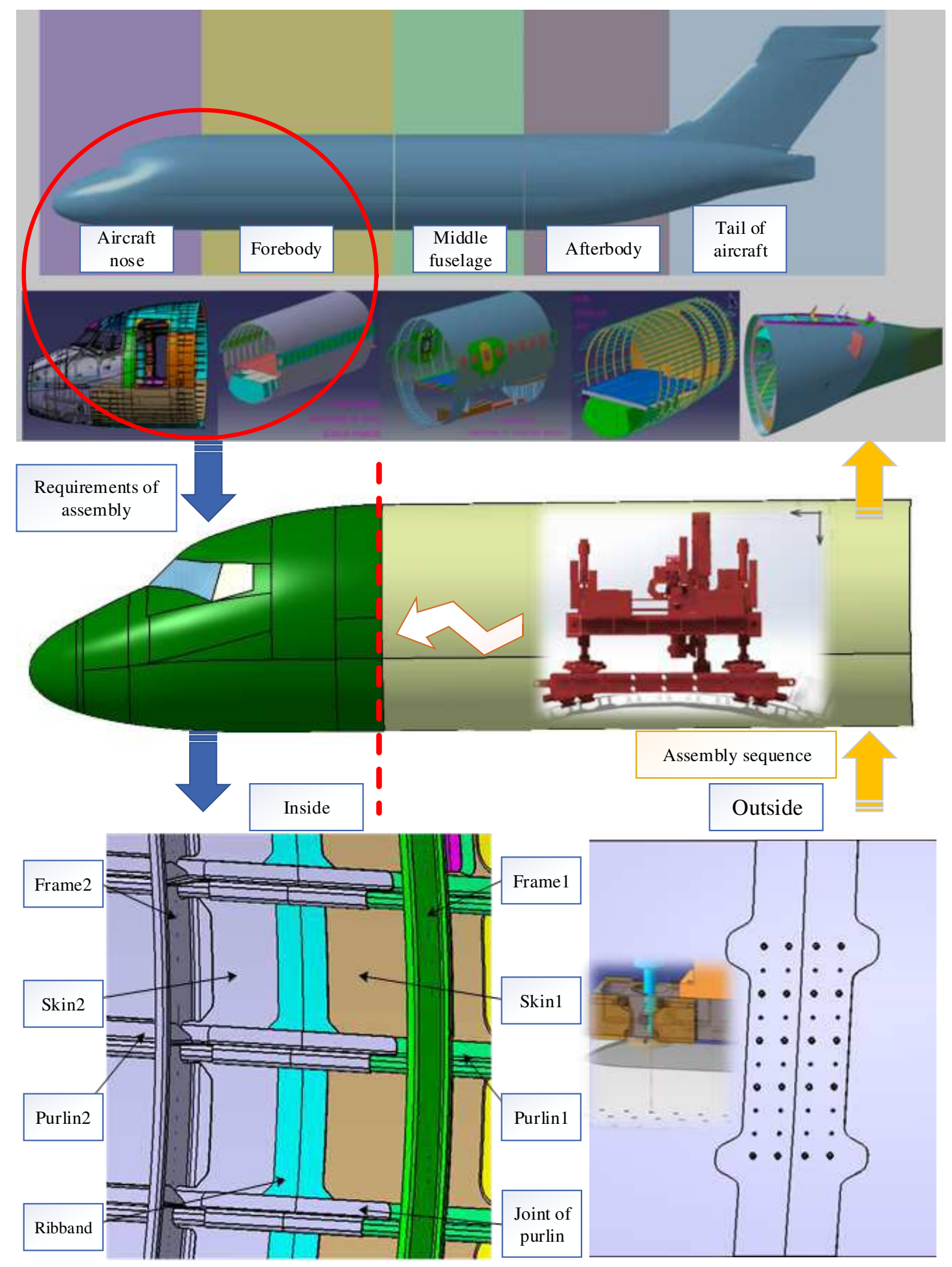

Fig.1 Requirements of aircraft analysis

\subsection{Flex track hybrid robot for drilling}

In order to improve production efficiency and assembly quality, aircraft assembly technology is developing towards automation, flexibility and low cost. Digital assembly technology is adopted in large component assembly to reduce the use of assembly tools such as mold frame and realize 
automatic flexible assembly.

Precision flexible automatic drilling equipment and technology have been widely used and developed in aircraft assembly at home and abroad. It mainly includes but is not limited to industrial robot drilling system, flexible drilling system, parallel machine flexible drilling equipment, portable automatic drilling system, etc., which can cover any production and assembly site to achieve precision hole making task, which lays a foundation for digital assembly of aircraft.

Comparing with industrial robot drilling system, machine tool drilling system and other automatic systems, the rigid-flexible track hybrid automatic drilling system independently developed by Nanjing University of Aeronautics and Astronautics mainly has the advantages of flexible, compact, maintainable and suitable for different shapes and sizes of the fuselage skin. It makes up for the defects of other automatic hole making systems such as large volume, poor versatility and tedious maintenance, and also meets the requirements of high precision automatic hole making for the assembly of large parts of aircraft fuselage. The basic structure of flexible track hybrid robot for drilling in abutting joint between the nose and the front fuselage of large aircraft components is shown in Fig 1.

Flexible track hybrid robot is composed of flexible track, parallel base, cross slide table and end-effector, etc. Powerful vacuum suckers are uniformly deployed at the bottom of the flexible track, which are adsorbed on the skin surface of the aircraft. Both sides of flexible track are clamped by a kind of V-wheel at the bottom of parallel base and connected as a whole. The parallel base is composed of four column legs and a rectangular inner frame, which connects the four legs to form a closed and stable parallel mechanism. Each column leg is equipped with a linear guide rail and ball screw, and a servo motor is installed on the top to realize independent drive of each leg. The end-effector comprises a mechanical spindle, a pressure angle shaft, a laser detector and a grating ruler, etc. Both of drilling feeding and pose adjustment are realized by four axis synchronous feeding and relative motion of parallel base. Four-axis parallel servo motor drives the whole parallel base downward along the direction of parallel legs, so as to drilling. Based on normal deviation detected by pressure angle of end-effector, the motor driving instructions of each leg of four shafts are calculated through inverse kinematics algorithm, and different vectors are executed by servo motors of each shaft, so as to adjust the normal deviation between drilling tool and aircraft skin and reduce it to target range. 

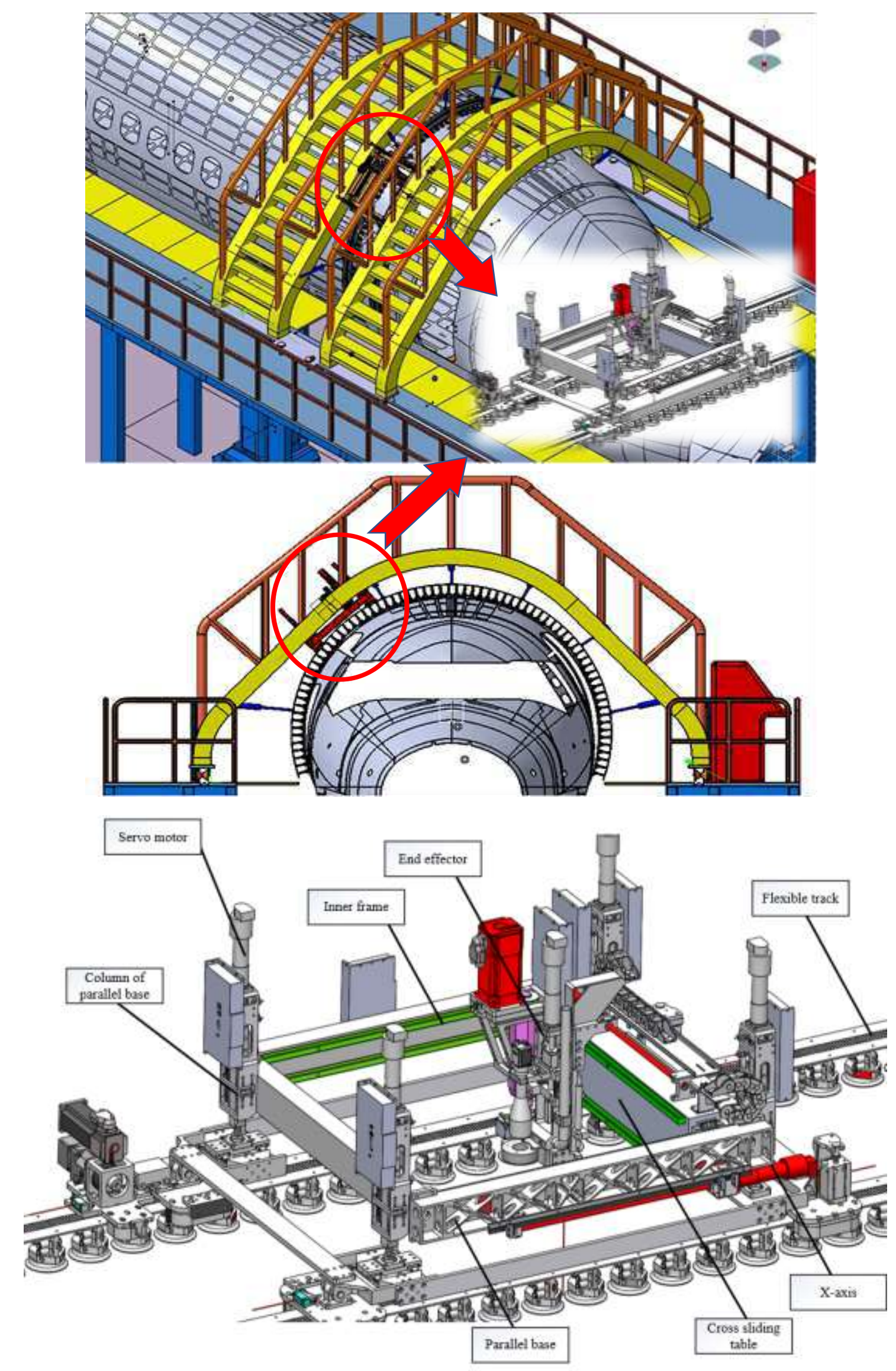

Fig.2 Structure diagram of flexible track hybrid robot for automatic drilling 


\subsection{Analysis of position error cause}

The process layout and equipment working station of flexible track hybrid robot for fuselage assembly are shown in Fig.3. The technics design of aircraft assembly is to complete drilling task of ribband and aircraft skin on joint area between the nose and the front of aircraft around the fuselage. Therefore, flexible track is laid around fuselage joint area, paralleling to fuselage joint ring seam area. $\mathrm{X}$-axis direction of cross slide table is parallel to the direction of flexible track laying along the joint area. The design size of $\mathrm{X}$ axis stroke is consistent with the distance between two purlins in joint area, so that the drilling range in each station is between the two purlins. When performing the drilling task, automatic drilling robot moves to the designated station along the flexible track that has been laid. According to prefabricated benchmark hole on the ribband between two purlins, the drilling task is carried out. There are three main conditions of drilling deviation, such as hole spacing deviation, hole overlapping, hole deviation along the axis, etc.

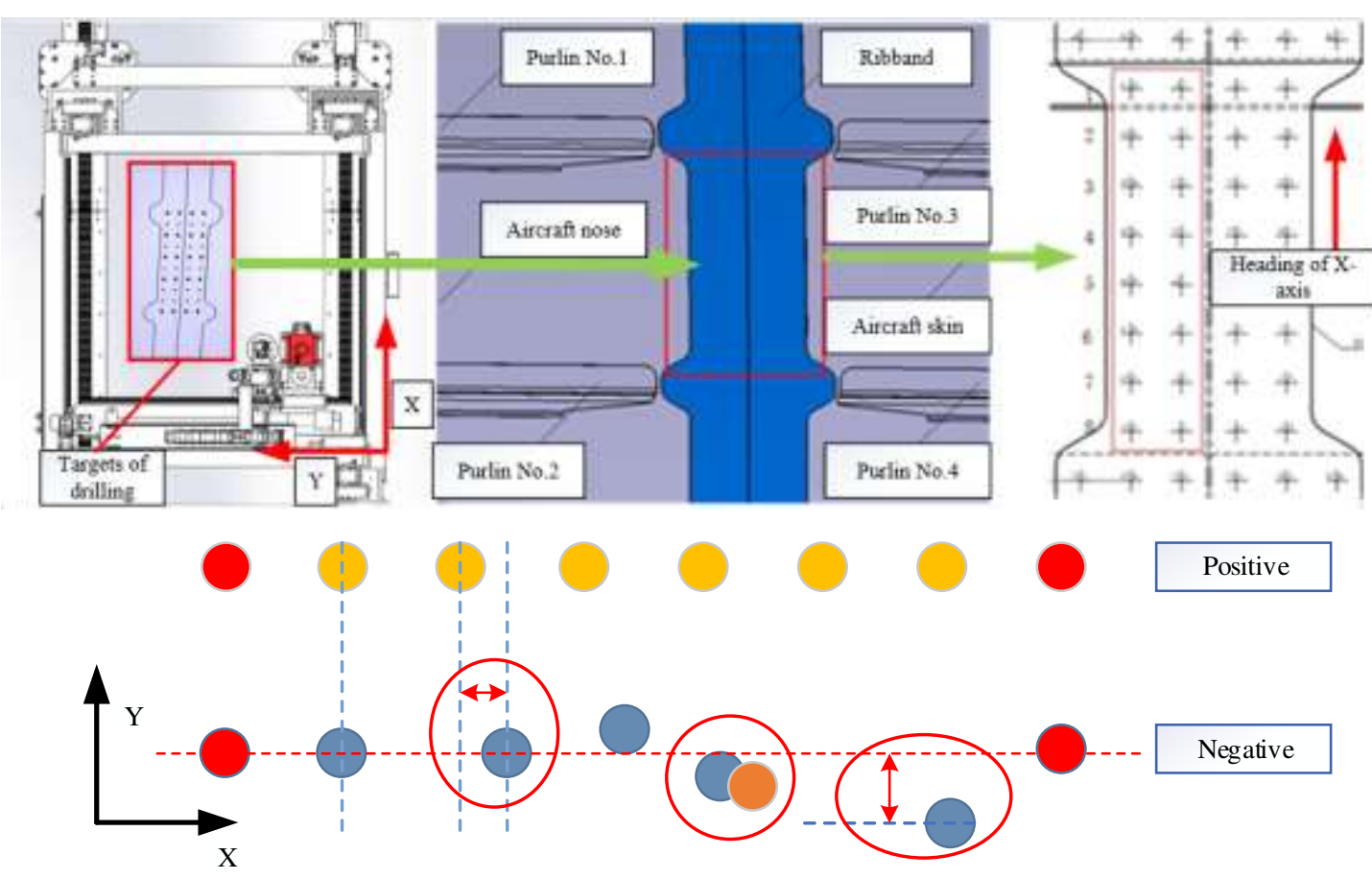

Fig.3 Process requirements of the joint area between nose and front fuselage

Apparently, the technical requirements of assembly docking area between the front fuselage and the nose of the aircraft and the application scenarios of flexible track hybrid robot for automatic drilling put forward strict requirements for positioning precision of the $\mathrm{X}$-axis. According to the process requirements, there are only four holes in the $\mathrm{Y}$ direction, while there are eight rows of holes in the $\mathrm{X}$ direction. In established process station, the high-precision positioning of hole location is realized only 
by relying on $\mathrm{X}$ and $\mathrm{Y}$ axes of the cross slide table to drive the spindle and cutter to specified position. Obviously, if the positioning precision of $\mathrm{X}$ axis is not enough, then the precision of automatic hole drilling task which executed after detection of benchmark is more difficult to guarantee. The longer length in hole drilling area, the greater cumulative error. Not only the positioning precision of a single hole, but also the straightness deviation of row hole location, which will seriously restrict the quality of riveting in the area.

Meanwhile, the structure characteristics and the way of drive shaft layout of flexible track hybrid robot for automatic drilling restrict positioning accuracy of $\mathrm{X}$-axis, due to the comprehensive factors such as heavy load, bias single drive and lever action. At the beginning of design, in order to reduce overall size and mass of equipment, compact structure, reduce the center of gravity, balance the counterweight for easy lifting and other factors, the $\mathrm{X}$ direction drive shaft cannot be arranged in the middle of the cross slide table. Moreover, due to the constraints of spatial layout and overall quality, the dual-axis layout and synchronous driving method cannot be adopted. Eventually, the $\mathrm{X}$-axis servo motor with the lead screw is mounted on the outside of the bottom of the inner frame. However, the $\mathrm{X}$ axis is required to drive the entire end-effector and cross slide table, and the lead screw is subjected to much heavier drag than the $\mathrm{Y}$ axis. At the same time, because of the driving force operating point is not at the central position, the parallel linear guide rail on both sides of the cross slide table bears a certain torsional moment, resulting in the positioning precision of $\mathrm{X}$-axis showing nonlinear characteristics.

To sum up, positioning error compensation should be carried out for $\mathrm{X}$ axis. The positioning precision of $\mathrm{X}$ axis directly determines the positioning precision of global hole drilling, the distribution of row holes and the precision of hole arrangement. Compensating the $\mathrm{X}$-axis positioning error is to compensate the comprehensive positioning error and improve the comprehensive positioning precision. Just like Cannikin Law, the so-called compensation is to complement the shortest board, that is, compensation of the worst precision of the drive shaft.

\subsection{Method of positioning error compensation}

The positioning precision compensation principle based on Response Surface Methodology is to use statistical method to collect part of the positioning error data, draw the positioning error curve, and analyze the characteristics of the positioning error. Then, the fitting method corresponding to the 
characteristics of positioning error is selected to establish the prediction model of global positioning error, and the compensation of position coordinates is realized through the prediction of positioning error at last. The process of compensation method is shown in Fig.4.

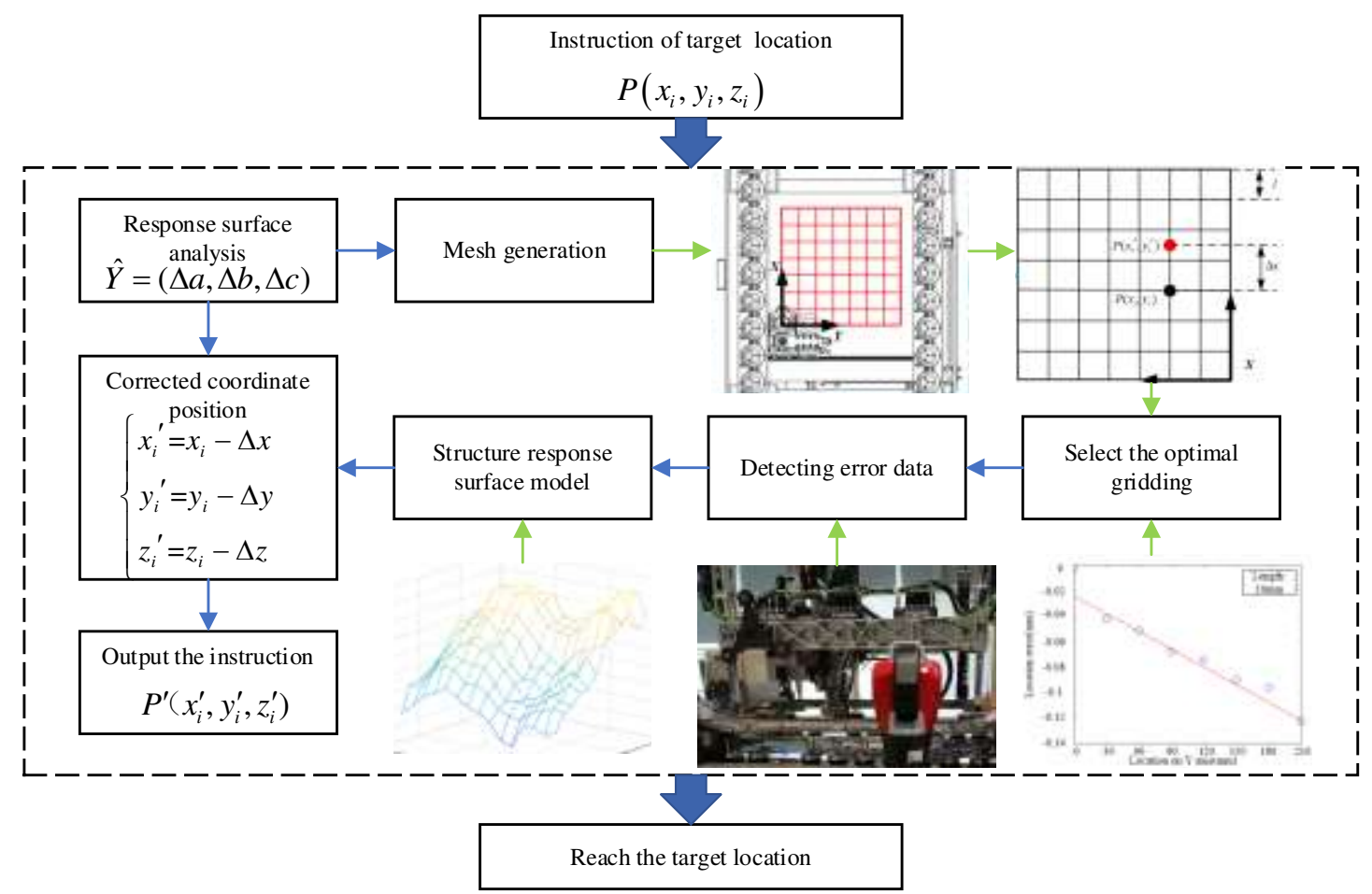

Fig.4 Flowchart of precision compensation method based on response surface method

Response Surface Methodologies[24] is an optimization method that integrates experimental design and mathematical modeling. It conducts experiments at representative local points, regresses the functional relationship between factors and results in the global scope, and finally obtains the optimal solution of each factor. By collecting the set of sample points in the design space, the global approximation of the output variable (system response) is fitted, which approximates the real response surface. In the engineering optimization design, response surface method is widely used. It can not only establish the relationship between the target response and the design variables, but also obtain the optimization method[25], so that the objective function can reach the optimal. The prediction of the target test can be more accurate and more consistent with the actual situation.

At present, there are polynomial, exponential function, logarithmic function fitting and neural network approximate methods to construct response surface methods. Among them, polynomial regression approximates complex function relations with relatively simple polynomials, especially in nonlinear regression[26], which shows the characteristics of simplicity and small computation. Usually, a low-order polynomial approximation is used within a certain range of design variables. In general, a 
second-order polynomial approximation model is[27]

$$
Y=\beta_{0}+\sum_{i=1}^{k} \beta_{i} x_{i}+\sum_{i=1}^{k} \beta_{i j} x_{i} x_{j}
$$

Where $\beta_{0}, \beta_{i}, \beta_{i j}$ is the unknown coefficient.

In order to distinguish, let denote $x_{1}$ the $\mathrm{X}$-axis position coordinate variable, denote $x_{2}$ the $\mathrm{Y}$-axis position coordinate variable, denote $x_{3}$ the z-axis position coordinate variable, then the design variable is

$$
X=\left[x_{1}, x_{2}, x_{3}\right]^{T}
$$

write it in matrix form

$$
Y=B X
$$

The key of polynomial model fitting is to solve the unknown coefficient vector. The response surface and unknown coefficient vector can be solved by analyzing the unknown coefficient vector by least square method[28]

$$
B=\left[X^{T} X\right]^{-1} X^{T} Y
$$

Generally, the fitting effect of the response surface was evaluated by Coefficient of determination $\left(r^{2}\right)$ and Root mean square deviation[29]. The root mean square deviation (RMSD) represents the sample standard deviation of the difference between the predicted value and the observed value. The determination coefficient is used to evaluate the goodness of fit of the regression model coefficients. The calculation formula[30] for both is as follows

$$
\begin{gathered}
\sigma_{R M S D}=\sqrt{\frac{\sum_{i=1}^{n}\left(y_{i}^{\prime}-y_{i}\right)^{2}}{n}} \\
r^{2}=1-\frac{\sum_{i=1}^{n}\left(y_{i}^{\prime}-y\right)^{2}}{\sum_{i=1}^{n}\left(y_{i}^{\prime}-\bar{y}\right)^{2}}
\end{gathered}
$$

For the selection of appropriate sample size to construct the response surface, the working plane of end-effector is evenly partitioned according to the established grid size, as shown in Fig.5. Where, the grid side length is $l$; each theoretical coordinate position $\left(x_{i}, y_{i}, z_{i}\right)$ is equally divided according 
to the grid step size. The actual target position $\left(x_{i}^{\prime}, y_{i}^{\prime}, z_{i}^{\prime}\right)$ is detected by the laser tracker, and the difference between the actual coordinate position and the theoretical coordinate position is the corresponding positioning error $\Delta x$.

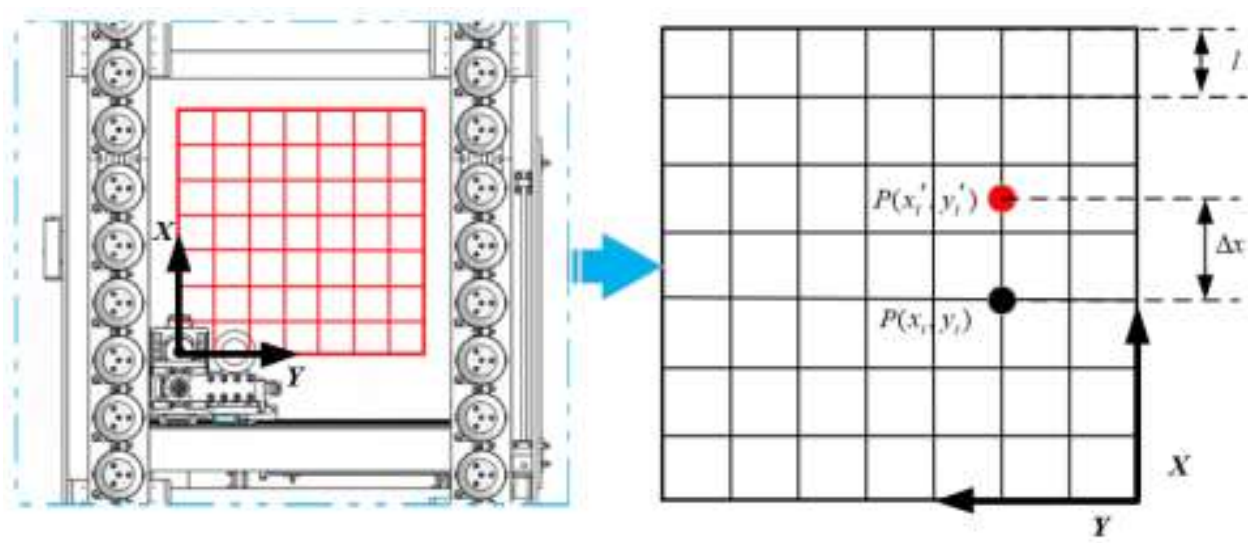

Fig.5 Schematic diagram of gridding principle

In the range of $(\mathrm{X}, \mathrm{Y})$ plane travel, the $\mathrm{X}$-axis positioning error at any point can be predicted by the response surface fitted by each detection error. The specific steps of constructing response surface to predict positioning errors are as follows:

1) Detect the positioning errors at all grid intersections within the entire travel range; According to the established grid intersection point coordinates as the instruction position $\left(x_{i}, y_{i}, z_{i}\right)$, the actual position coordinates are detected and compared with the instruction position $\left(x_{i}^{\prime}, y_{i}^{\prime}, z_{i}^{\prime}\right)$, and the error distribution curve of the ball screw on the full travel is calculated;

2) According to the characteristics of the error distribution curve, the corresponding response surface fitting method was selected, and the location coordinates of $\mathrm{X}, \mathrm{Y}$ and $\mathrm{Z}$ axes were taken as the design variables, and the positioning error was taken as the response target to calculate the regression equation of the positioning error surface;

3) Calculate the error prediction value of the instruction position coordinates by using the fitting positioning error regression equation input from any instruction position coordinates: $\hat{Y}(\Delta a, \Delta b, \Delta c)$.

Not only to make more accurate fitting by the response surface, but also to meet the precision requirement of conditions as far as possible reduce the number of sampling points, putting forward a method of optimal gridding, to assess the effect of grid length and fitting precision, so that to make the optimal analysis of grid length detection area. The specific method is as follows: in the whole travel area, the positioning error data is collected by groups according to the length of different grids; Then, 
the least square regression method was used to fit the error data of different grids, and the residual mean value of each group of regression equation was calculated based on the regression equation of positioning error data fitting. Finally, by comparing the fitting residuals of different grid partitioning, the optimal grid size length with relatively small fitting residuals and relatively small grid partitioning number was selected.

Relationship of different grid step for the positioning error of the regression model fitting the data, as shown in Fig.6. As we can see, the grid size is smaller, the better fitting effect, the smaller the offset of the measured data with the regression model, that is, to the least squares fitting error of the positioning error of forecasting results and actual values between the residual error is smaller, the more fully and accurately predict the change trend of actual positioning error.

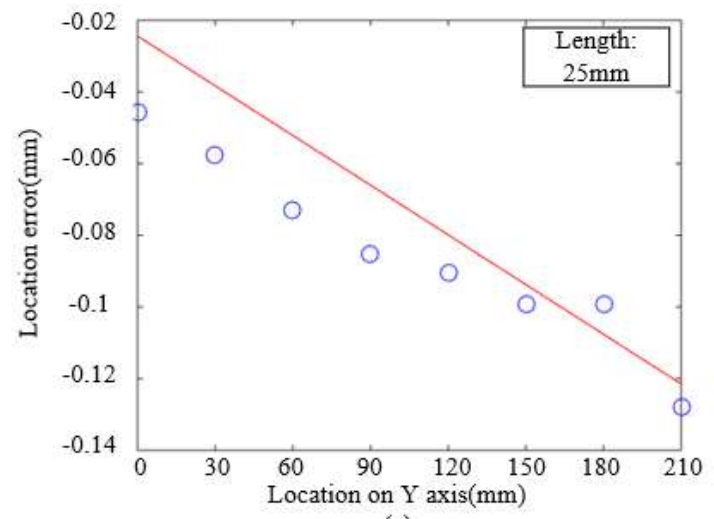

(a)

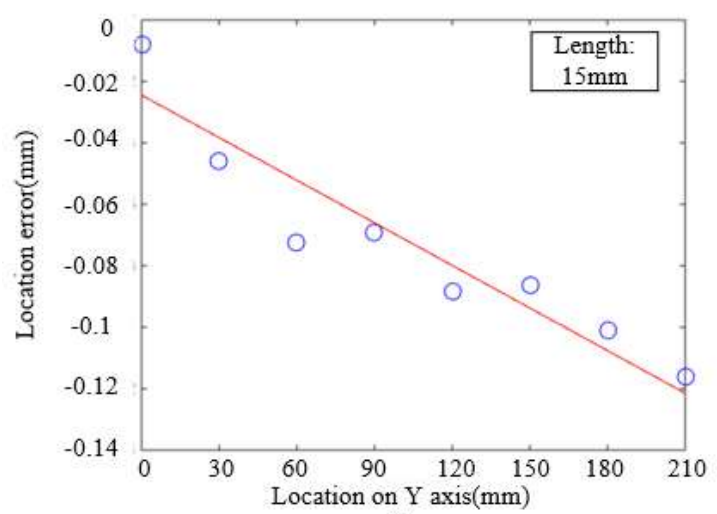

(c)

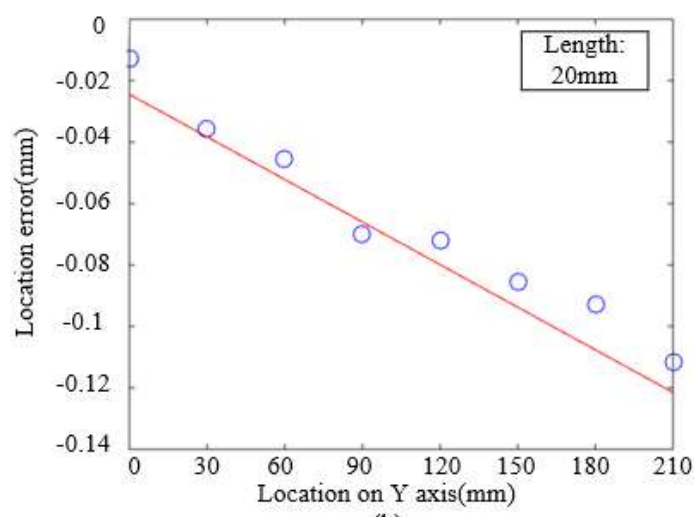

(b)

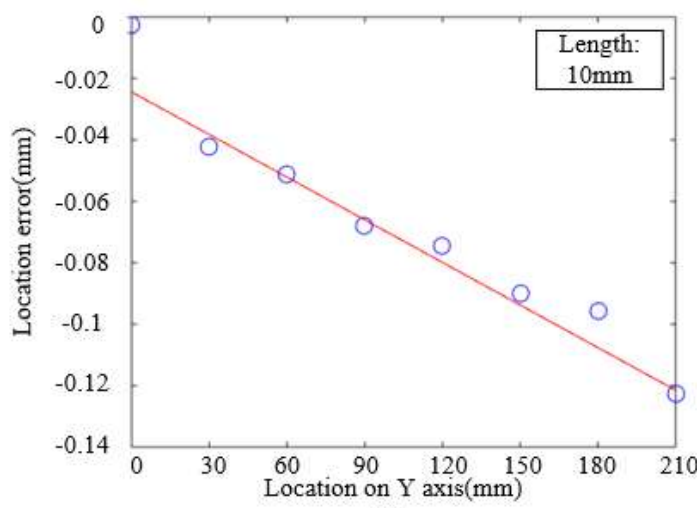

(d)

Fig.6 Regression fitting data under different gridding length

Residuals of the regression model fitted with different grid size are shown in Fig.7. The residual value of regression fitting increases with the increase of grid size. In all sample points with positioning errors, the residual values within the grid size of $20 \mathrm{~mm}$ are all less than $0.02 \mathrm{~mm}$, which has little influence on the goodness of fit of the response surface. The finer the grid dividing step is, the smaller the residual value is, and the better the fitting effect is. Meanwhile, considering the test detection error, 
the influence on the fitting precision when the residual value is less than $0.02 \mathrm{~mm}$ can be ignored. Therefore, in order to meet the fitting precision and relatively reduce the number of samples, the grid size of $20 \mathrm{~mm}$ was selected as the relative optimal solution.

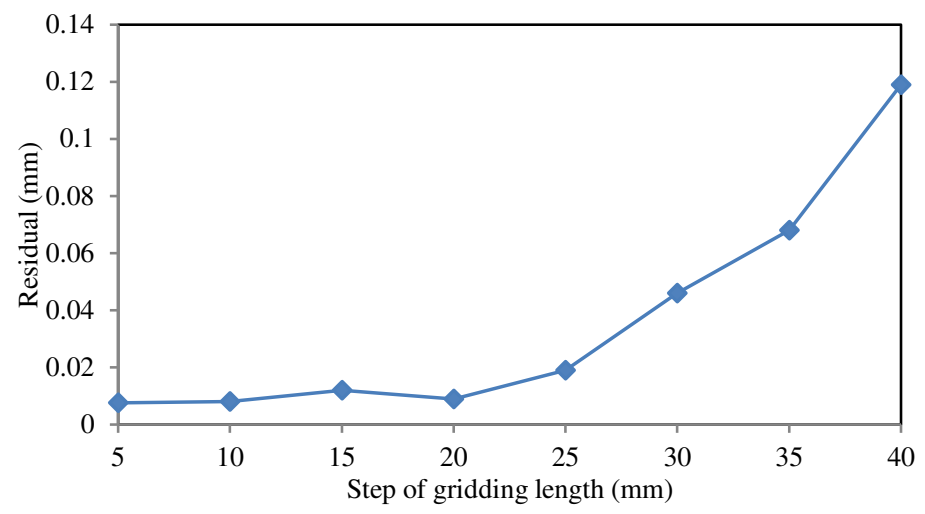

Fig.7 Relationship between grid size and fitted residuals

\section{Experiment and verification}

\subsection{Design of experiment}

In the test, the end-effector of the hybrid robot assembly for the fuselage was used as the carrier, and the position of the end-effector was measured by API-T3 laser tracker. The test site is shown in Fig.8. The laser tracking target Spherically Mounted Reflector (SMR) is mounted on the spindle of the end-effector of the robot. During the measurement process, the position and attitude of the orbit robot remain fixed and the end-effector is only driven by the motor instruction. 


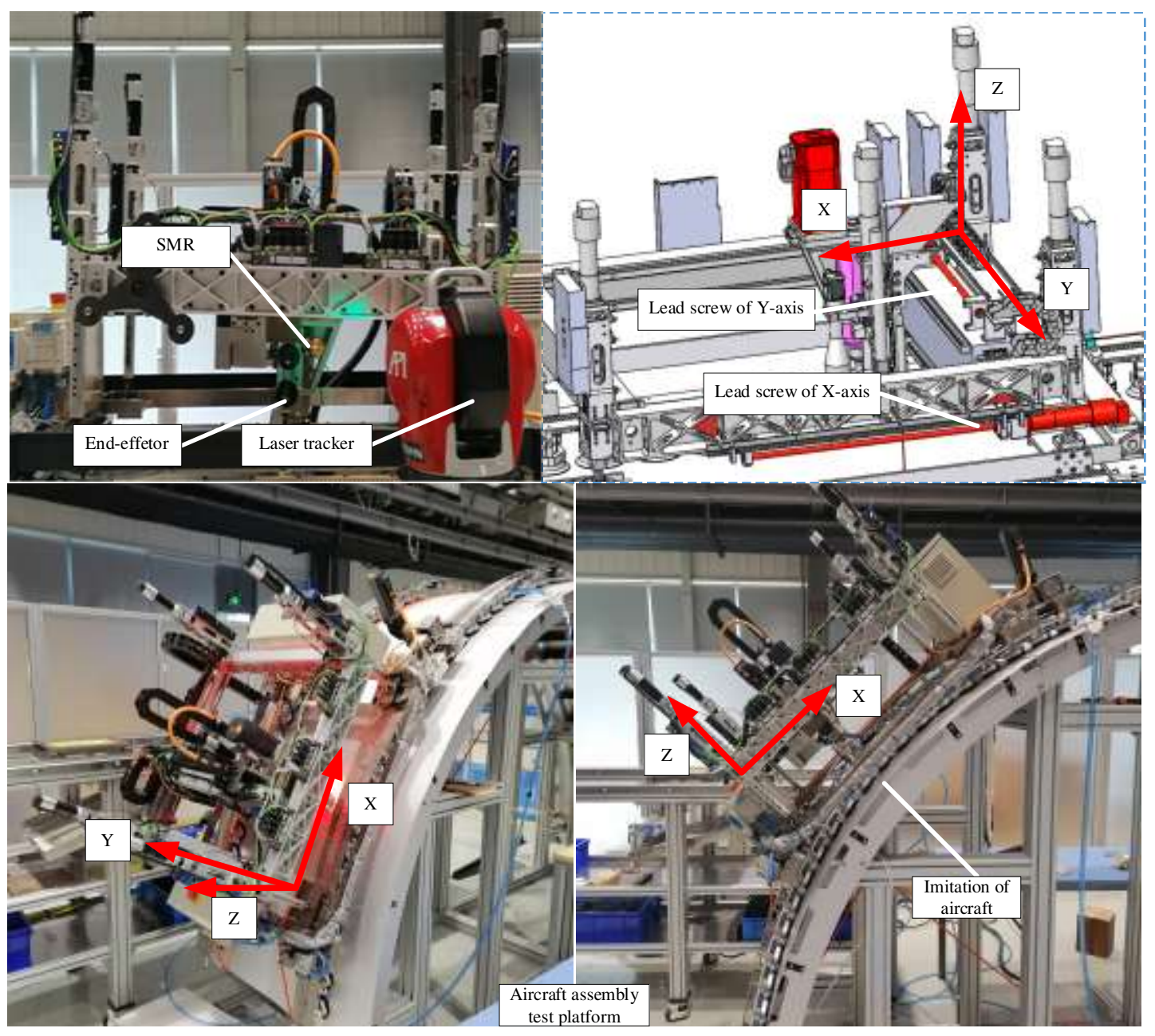

Fig.8 Experimental design and coordinate axis of flexible track hybrid robot

Both the sampling point and the instruction coordinate point are relative to the robot coordinate system, and the point coordinates measured by the laser tracker are also relative to the robot coordinate system. The steps to establish the robot coordinate system are as follows:

1) The end-effector returns to zero and collects the zero position as the origin of the base coordinate system $O$;

2) Drive the $X$ axis to move a certain distance, use the laser tracker to measure and obtain the point set, and then fit the $\mathrm{X}$ axis.

3) Similarly, $\mathrm{Y}$ axis and $\mathrm{Z}$ axis are driven respectively according to the same method. Laser tracker is used to measure and obtain point sets, and $\mathrm{Y}$ axis and $\mathrm{Z}$ axis are fitted.

4) Three features (coordinate origin, $\mathrm{X}, \mathrm{Y}$ and $\mathrm{Z}$ axis) are obtained through the above steps to establish the robot coordinate system.

After the robot coordinate system is established, the working travel is divided according to the optimal grid, and the positioning error within the full travel is detected and calculated. The 
experimental detection steps are shown in Fig.9.

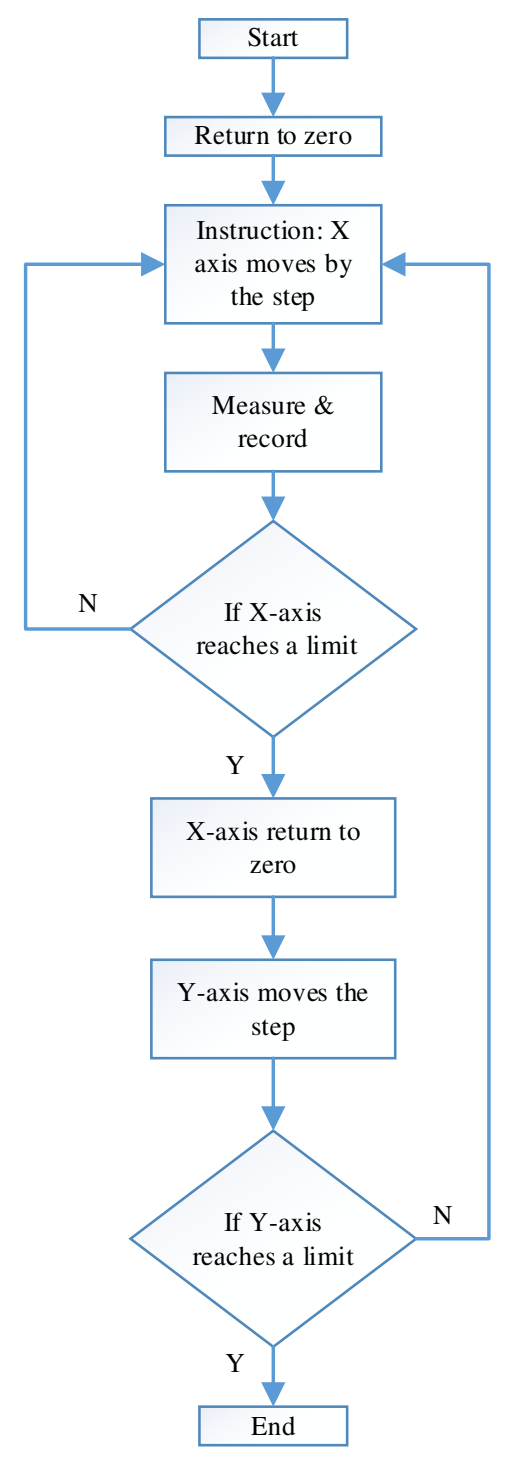

Fig.9 Absolute positioning error detection program

\subsection{Analysis of experimental data}

Before constructing the response surface approximation model, the relationship between the design variables and the analysis target should be preliminarily analyzed qualitatively, so as to choose the appropriate functional form to quantitatively describe the relationship between the design variables and the response target. According to the detection scheme, a total of 180 grid intersecting point coordinates positioning errors were obtained within the travel range, which were plotted into a broken line diagram as shown in Fig.10. In the plane of the end-effector (X, Y), motors and ball screws of the same specifications are used for both $\mathrm{X}$ and $\mathrm{Y}$ axes. However, the absolute positioning error of $\mathrm{X}$ axis 
is much larger than that of $\mathrm{Y}$ axis, and the absolute positioning error of $\mathrm{X}$ axis is nearly ten times larger than that of $\mathrm{Y}$ axis and $\mathrm{Z}$ axis. Obviously, the absolute positioning precision of $\mathrm{X}$ axis determines the comprehensive positioning precision. Since the X-axis positioning error plays a decisive role in the comprehensive positioning error, only the $\mathrm{X}$-axis positioning error is taken as the response target to carry out the research. The mean value of all positioning errors in the sample points: $-0.0578 \mathrm{~mm}$, the standard deviation: 0.0351; The positioning errors of the vast majority of point locations are negative, indicating that the actual point locations on the $\mathrm{X}$-axis are basically behind the target point locations and do not reach or exceed the actual point coordinates. The standard deviation value is about $60 \%$ of the mean value of the absolute positioning error, indicating that the sampling data has a high degree of dispersion, and the positioning error drift is large and the error is unstable.

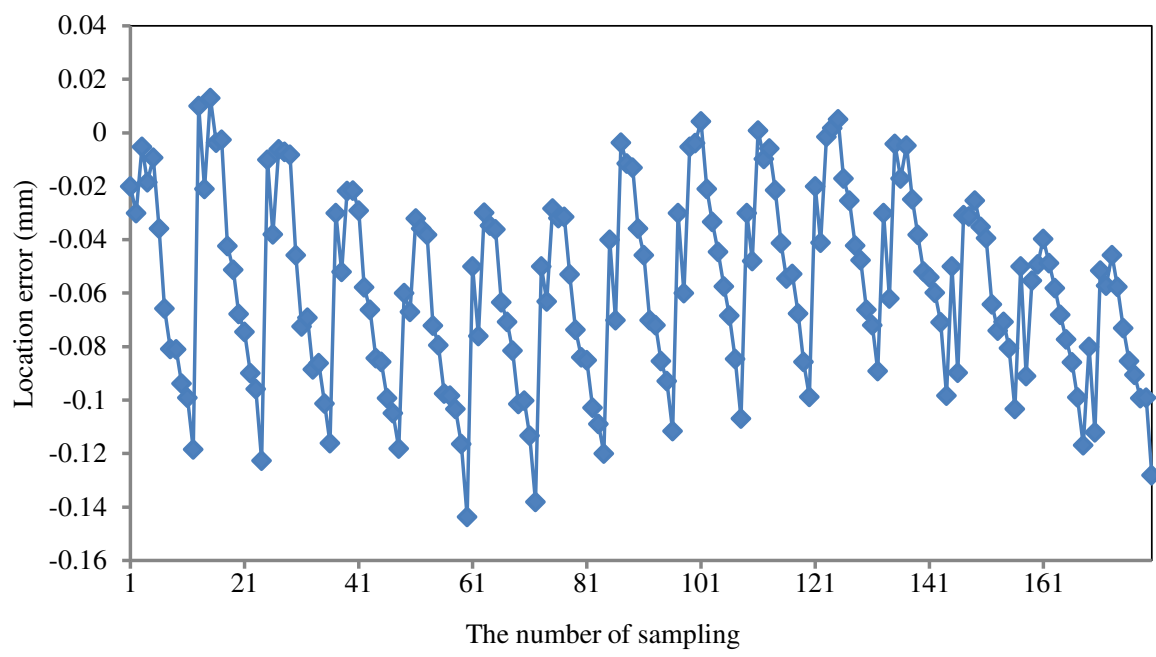

Fig.10 Location error data before compensation

In order to show the changing trend of positioning error more directly, three-dimensional views of positioning error in the $\mathrm{X}$-axis and $\mathrm{Y}$-axis plane are drawn with the positioning error value as the ordinate, as shown in Fig.11. Taking the abscissa as the $\mathrm{X}$-axis coordinate position, the ordinate as the positioning error value, and different $\mathrm{Y}$-axis coordinate positions as groups, a line chart of positioning error along the $\mathrm{X}$-axis direction is drawn, as shown in Fig.12. Within the working stroke of (X, Y) axis, the whole positioning error data presents a certain fluctuation along the $\mathrm{X}$ axis. The variation trend of positioning error data of different groups along the $\mathrm{X}$ axis is basically the same. The minimum value of positioning error is in the $\mathrm{Y}=0 \mathrm{~mm}$ position coordinate, and the maximum value is in the $\mathrm{Y}=220 \mathrm{~mm}$ position coordinate. Positioning error data are laid out in $\mathrm{X}$ and $\mathrm{Y}$ axis planes, representing by different color aberrations, as shown in Fig.13. It can be seen that, obviously, the area with high 
positioning accuracy is mainly near the drive shaft.

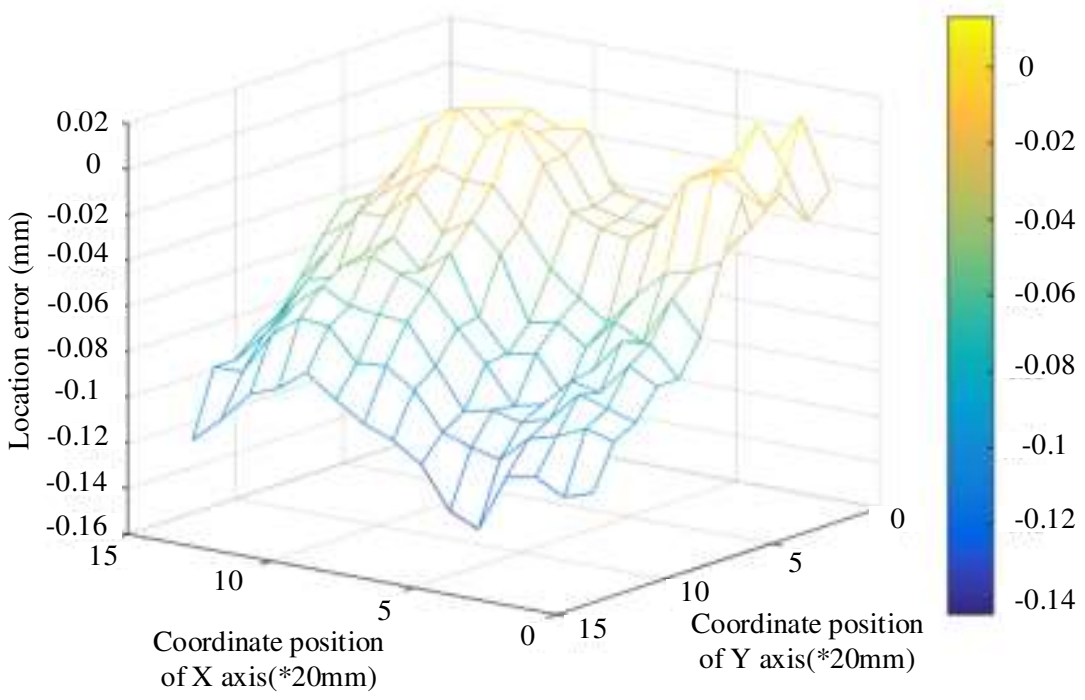

Fig.11 3D view of location error data before compensation

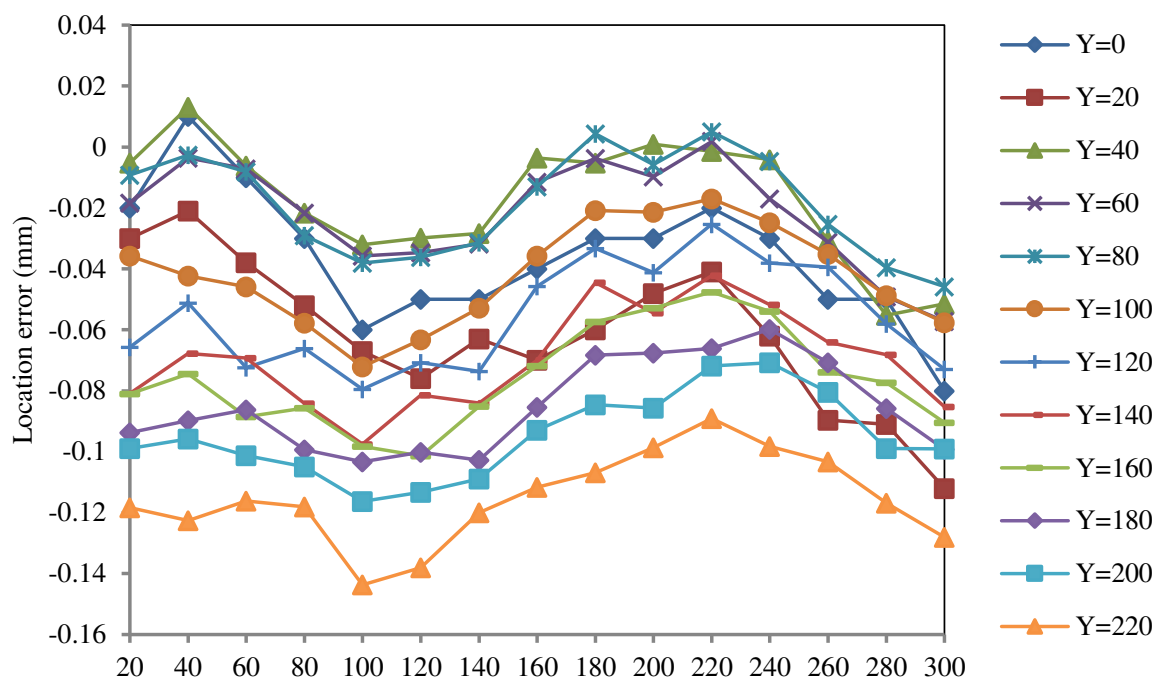

Coordinate position of $\mathrm{X}$ axis (mm)

Fig.12 Location error data grouped by $\mathrm{Y}$ axis 


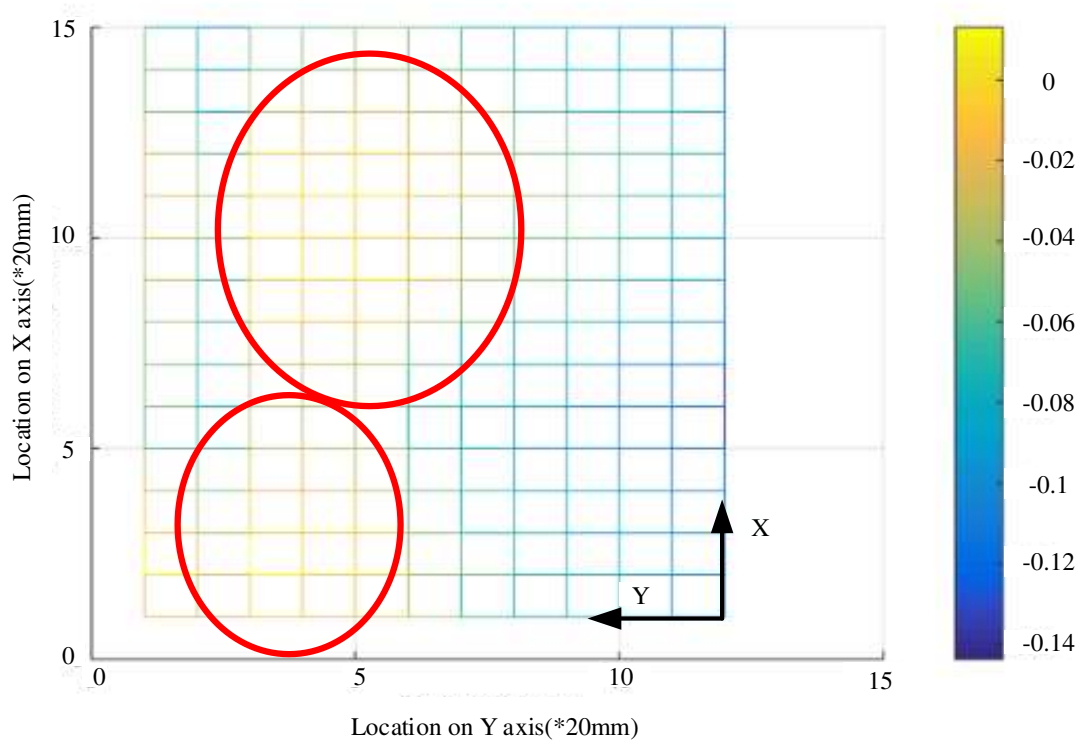

Fig.13 Positioning error data are laid out in $\mathrm{X}$ and $\mathrm{Y}$ axis planes

According to the 180 positioning error data detected above, the response surface of global positioning error was constructed, with combining the nonlinear characteristics of sampling positioning error and incremental feature with coordinate position, and selecting the method of polynomial fitting and error offset term increasing

$$
Y(x, y)=B X(x, y)+\varepsilon
$$

Where, $\varepsilon$ is the deviation term of fitting error.

The response surface determination coefficient of fitting is $99.6 \%$, and the root mean square deviation is 0.006 . The fitting precision of the response surface model is good, which is sufficient to meet the requirements of accurate prediction of positioning errors.

\subsection{Effect of precision compensation}

According to the regression equation fitted by the positioning error data, the $\mathrm{X}$-axis positioning precision compensation algorithm was programmed into the numerical control system. Based on the same test conditions, the compensated position error was measured with a laser tracker. During the experiment, the positions of the laser tracker and the hybrid robot are kept fixed. When the grid vertices are positioned, the orbital hole-making robot takes the stroke zero as the starting point, and the positions of all target points remain unchanged during the positioning and verification. In order to display the experimental results more intuitively, the absolute positioning precision of all target points measured was compared with the precision before compensation, and a line chart was drawn as shown 
in Fig.14. Take the relative ratio of the precision before and after the grid coordinate compensation of $\mathrm{Y}=0 \mathrm{~mm}$ and $220 \mathrm{~mm}$ to make a line chart, as shown in Fig.15 and Fig.16. The statistical comparison of the compensated mean, maximum and standard deviation is shown in Tab.1.

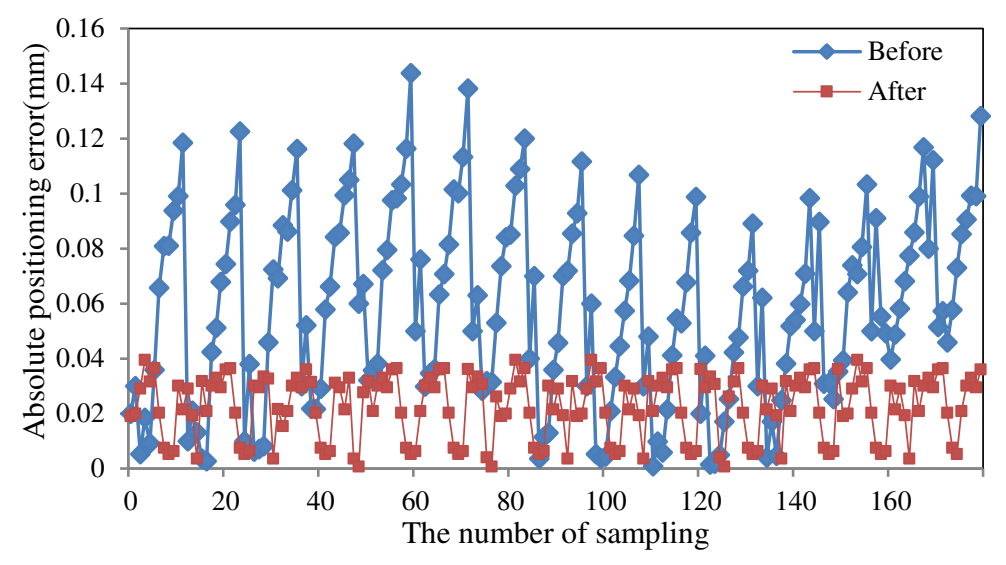

Fig.14 Comparison of absolute positioning error before and after compensation

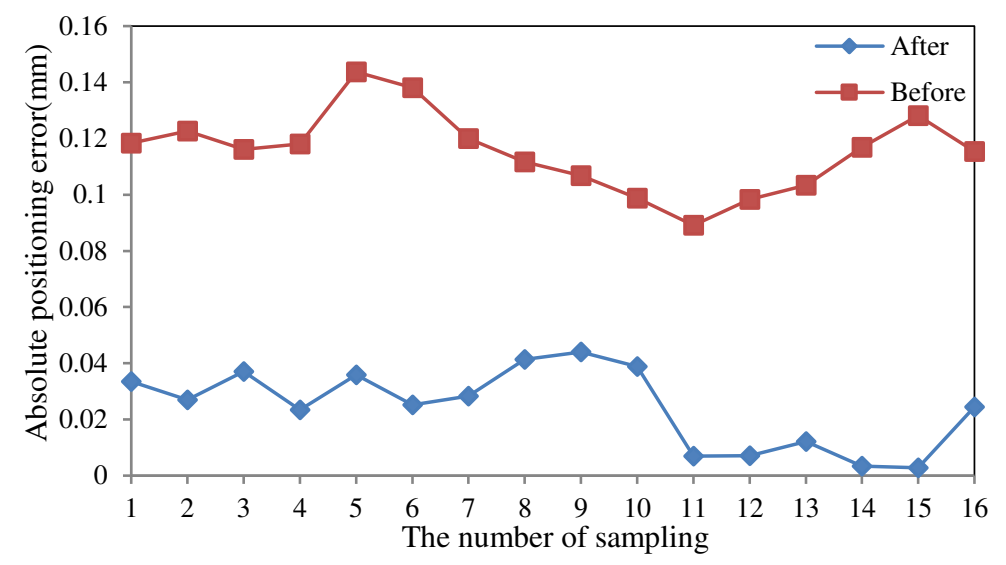

Fig.15 Comparison of positioning errors before and after optimization $(\mathrm{Y}=220 \mathrm{~mm})$

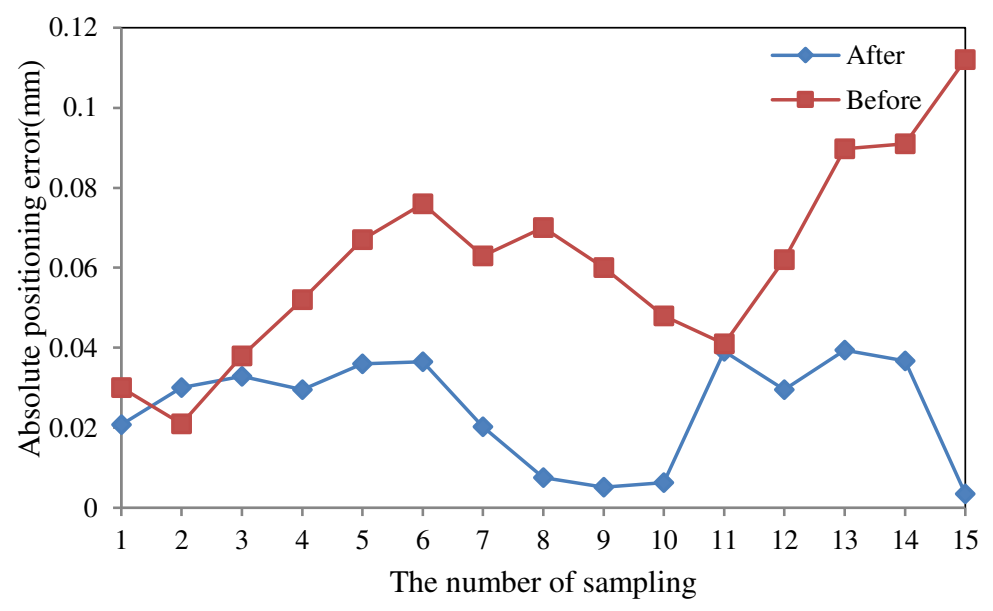

Fig.16 Comparison of positioning errors before and after optimization $(\mathrm{Y}=0 \mathrm{~mm})$ 
Tab.1 Mean and standard deviation of positioning error before and after optimization

\begin{tabular}{llll}
\hline Items & Before & After & Rate \\
\hline Average value & 0.081 & 0.025 & $69.1 \%$ \\
Standard deviation & 0.024 & 0.018 & $25.0 \%$ \\
Maximum & 0.143 & 0.039 & $72.7 \%$ \\
\hline
\end{tabular}

After compensation, the precision of 180 grid intersections is greatly improved, and the absolute positioning precision is all within $0.04 \mathrm{~mm}$. The maximum absolute positioning error is $0.039 \mathrm{~mm}$, which is $72.7 \%$ lower than that of $0.143 \mathrm{~mm}$ before compensation. The mean value was $0.025 \mathrm{~mm}$, which decreased by $69.1 \%$ compared with $0.081 \mathrm{~mm}$ before compensation. Compared with before compensation, the standard deviation is reduced by $25 \%$ and the error offset is reduced.

In order to fully verify the effect of the precision compensation algorithm on final drilling task, two sets of drilling experiments were designed to compare the hole position accuracy before and after precision compensation. With the same set of datum holes as benchmark, in two different groups of drilling methods, one group adopts the compensation algorithm, the other group does not use the compensation algorithm, and the automatic drilling task is performed at uniform intervals along the $\mathrm{X}$ axis direction. The result of drilling is shown in Fig.17.

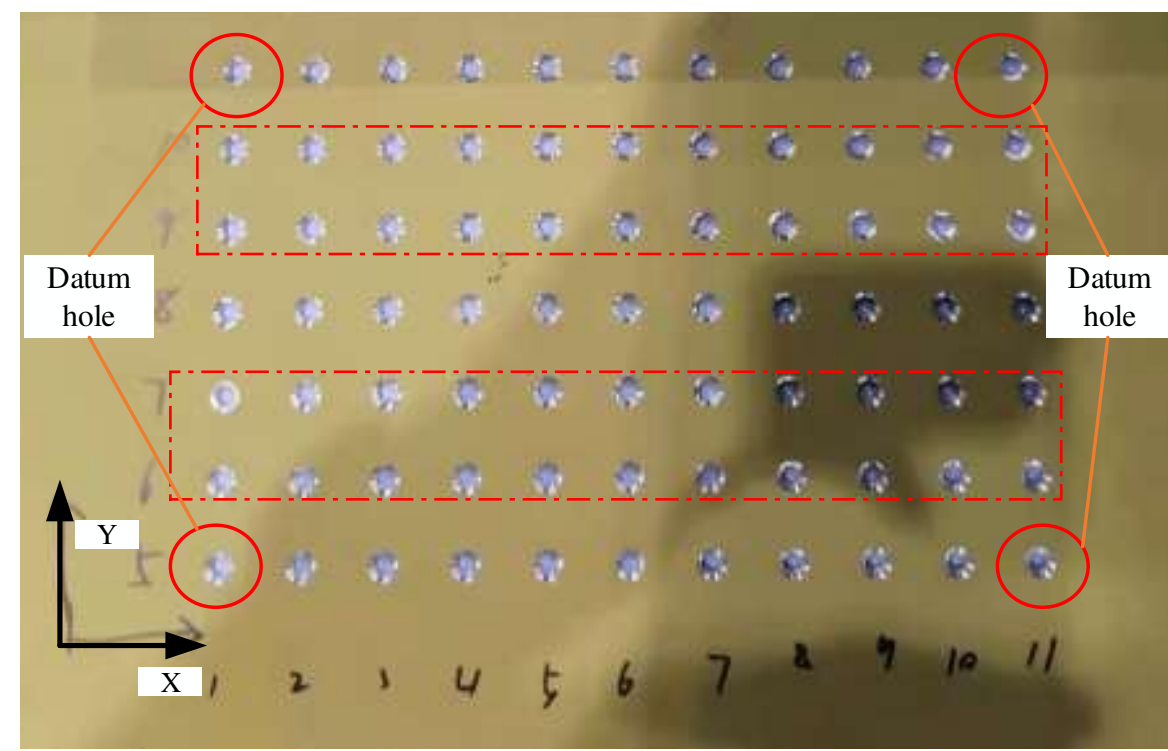

Fig.17 Results of drilling under different conditions

Taking the fitted center of datum hole as origin of coordinate system, a plane coordinate system was established to measure the coordinates of different holes. The geometric tolerance of each hole was detected by Coordinate Measuring Machine, and the two groups of data were fitted into one group to compare the positioning errors before and after compensation, as shown in Fig.18 and Fig.19. The equipment used for measurement and test conditions are shown in Tab. 2. 


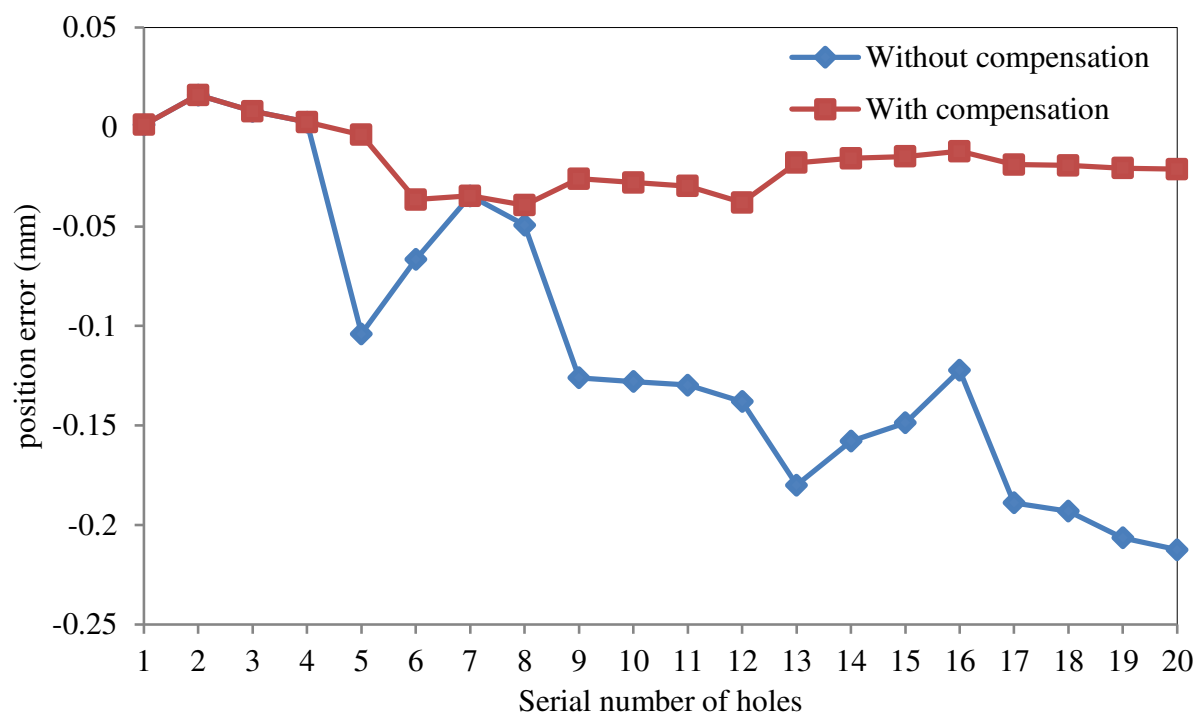

Fig.18 Positioning error of hole coordinates in $\mathrm{X}$ axis direction

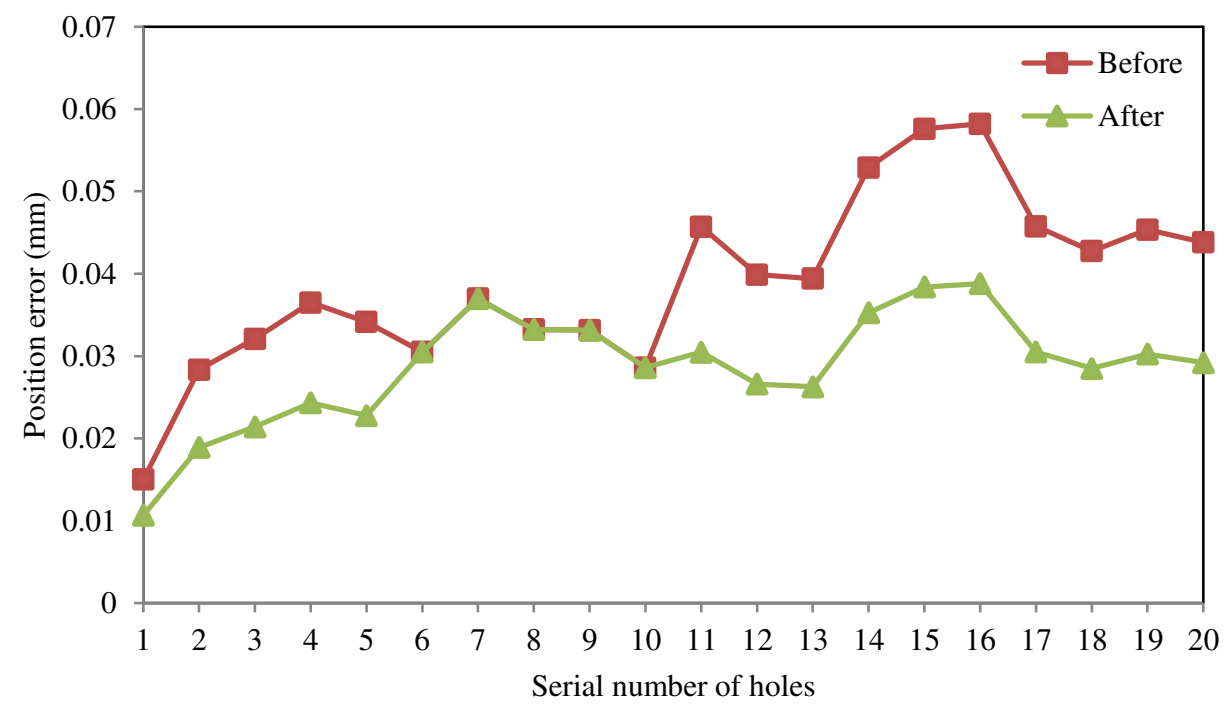

Fig.19 Positioning error of hole coordinates in $\mathrm{Y}$ axis direction

Tab.2 Measuring equipment and conditions

\begin{tabular}{|c|c|c|c|c|c|c|}
\hline Instruments & Accuracy class & & Test reference & Items & Temperature & Humidity \\
\hline UPMCS-ACC & $\pm(0.6+\mathrm{L} / 600)$ & $\mu m$ & GB/T 1958-2017 & Geometrical tolerance & $19.6^{\circ} \mathrm{C}$ & $47 \%$ \\
\hline
\end{tabular}

Before compensation, the cumulative error along the $\mathrm{X}$ axis is getting bigger and bigger. After compensation, the error tends to be flat, small and stable. The straightness of continuous drilling is expressed by deviation of the hole position Y axis coordinate. Relatively speaking, the straighter the error curve is, the more accurate trajectory of continuous automatic drilling can be. Before and after compensation, the deviation of the hole location in the direction of $\mathrm{Y}$ axis has no significant change, but the overall trend is more gentle. The positioning accuracy of the $\mathrm{Y}$ axis is also slightly affected by $\mathrm{X}$ axis, with the improvement of the positioning accuracy of the $\mathrm{X}$ axis, the positioning accuracy of the 
$\mathrm{Y}$ axis is also slightly improved.

The results show that the positioning precision of the hybrid robot compensated by response surface method is significantly improved, and the precision is more than doubled compared with that before the compensation. Moreover, the fluctuation range of the compensated positioning error is smaller and the error tends to be more stable.

\section{Conclusion}

(1) A precision compensation method based on response surface is proposed. Based on the analysis of the distribution characteristics of global positioning errors, a binary second-order response surface model was established to predict the $\mathrm{X}$ - and $\mathrm{Y}$-axis plane positioning errors.

(2) A gridding length optimization method is proposed. The least square method was used to fit the positioning errors of different grid size in the same area, and the relationship between different grid size and fitting residuals was revealed. The goodness of fit of response surface was improved by the grid size optimization method.

(3) After compensation, the absolute positioning precision of the hybrid robot is improved to $0.05 \mathrm{~mm}$, which is about $70 \%$ higher than before; The maximum positioning error is reduced to $0.039 \mathrm{~mm}$, which is reduced by $70 \%$ and the mean square error is reduced by $25 \%$. The error fluctuation is more stable, which is more suitable for the application scenario of the hybrid robot in the fuselage docking and assembling the configuration hole task.

(4) The results of experiments show that the method based on response surface precision compensation and optimization method of least square grid size for precision effect is remarkable. This method is accurate, simple, and has a small amount of computation, which effectively improves the application range of the hybrid robot for positioning precision.

(5) When constructing the response surface, the positioning error data of a single drive shaft, which has the greatest influence on the comprehensive positioning error, is adopted, while the pose error of the end-effector is ignored. The pose error compensation method of the end-effector still needs further study. 


\section{Funding}

National Science and Technology Major Project of the Ministry of Science and Technology of China (No. 2018ZX04006001-006) ; National Youth Science Foundation of China (No. 52005254).

\section{Competing interest}

The authors declared that they have no conflicts of interest to this work. We declare that we do not have any commercial or associative interest that represents a conflict of interest in connection with the work submitted.

\section{Availability of data and material}

The data sets supporting the results of this article are included within the article.

\section{Code availability}

Not applicable.

\section{Ethics approval}

Not applicable.

\section{Consent to participate}

Not applicable.

\section{Consent for publication}

We confirm that this work is original and has not been published elsewhere, nor is it currently under consideration for publication elsewhere. All the authors listed have agreed to publish the manuscript that is enclosed. 


\section{Authors' contributions}

Zhihao Li: Test Design, Test execution, Software, Data analysis, Writing-Original draft preparation. Wei Tian: Test Design, Investigation, Reviewing and Editing, Project administration. Min Wang: Investigation, Supervision, Reviewing and Editing. Bo Li: Validation, Project administration, Writing-Reviewing and Editing. Wenhe Liao: Writing-Reviewing and Editing.

\section{Acknowledgements}

The authors are grateful to the support by National Science and Technology Major Project of the Ministry of Science and Technology of China (No. 2018ZX04006001-006) and the National Youth Science Foundation of China (No. 52005254).

\section{References}

[1] Vosniakos G, Angelidis A (2014) Prediction and compensation of relative position error along industrial robot end-effector paths. International Journal of Precision Engineering \& Manufacturing 15(1):63-73.

[2] Zhang J, Wang X, Wen K, et al (2018) A simple and rapid calibration methodology for industrial robot based on geometric constraint and two-step error. Industrial Robot 45(6): 715-721.

[3] He Q, You Z, Kong X (2016) Positioning error compensation method of industrial robot based on closed-loop feedback of position and orientation. China Mechanical Engineering(Chinese) 27(07): 872-876.

[4] Jayswal D, Taufik M (2011) Modeling And Analysis Of The Surface Roughness And Geometrical Error Using Taguchi And Response Surface Methodology. International Journal of Engineering Science \& Technology 3(7): 521-534.

[5] Wei T, Mei D, Li P, et al (2015) Determination of optimal samples for robot calibration based on error similarity. Chinese Journal of Aeronautics 28(03): 946-953.

[6] Tian W, Zhou W, Wei Z, et al (2013) Auto-normalization algorithm for robotic precision drilling system in aircraft component assembly. Chinese Journal of Aeronautics 26(002): 495-500.

[7] Zhou W (2013) Theory and Experiment of Industrial Robot Accuracy Compensation Method Based on Spatial Interpolation. Journal of Mechanical Engineering(Chinese) 49(3): 42-48.

[8] Wang L, Li X, Zhang L, et al (2018) Analysis of the Positioning Error of Industrial Robots and Accuracy Compensation Based on ELM Algorithm. Robot 40(6):843-859.

[9] Zhang G, To S, Xiao G (2014) A novel spindle inclination error identification and compensation method in ultra-precision raster milling. International Journal of Machine Tools \& Manufacture $78: 8-17$

[10] Zhao G, Wang D, Liu L, et al (2020) Positioning error compensation for parallel mechanism with two kinematic calibration methods. Chinese Journal of Aeronautics 33(09): 2472-2489. 
[11] Feng W, Li Z, Gu Q, et al (2015) Thermally induced positioning error modelling and compensation based on thermal characteristic analysis. International Journal of Machine Tools and Manufacture 93(6):26-36.

[12] Choi C, Liang L J, Li H Y, et al (2014) Study on Positioning Prediction of Ball Screw by Error Compensation System. Proceedings of the KSMPE Conference 66-66

[13] Guo X G, Wang D C, Li C X, et al (2002) A rapid and accurate positioning method with linear deceleration in servo system. International Journal of Machine Tools \& Manufacture 42(7):851-861.

[14] Zhang L, Gao J, Chen X (2018) A Rapid Dynamic Positioning Method for Settling Time Reduction Through a Macro-Micro Composite Stage With High Positioning Accuracy. IEEE Transactions on Industrial Electronics 65(6):4849-4860.

[15] Kwac L K, Kim J Y, Kim H G (2006) Compensation of Environment and Motion Error for Accuracy Improvement of Ultra-Precision Lathe. International Journal of Modern Physics B 20(25):624-633.

[16] Zhong G, Wang C, Yang S, et al (2015) Position geometric error modeling, identification and compensation for large 5-axis machining center prototype. International Journal of Machine Tools \& Manufacture 89:142-150.

[17] Wang C, Wei Pen, Ding, et al (2016) Actual inverse kinematics for position-independent and position-dependent geometric error compensation of five-axis machine tools. International Journal of Machine Tools \& Manufacture Design Research \& Application 55-62.

[18] Gan S W, Han-Seok L, Rahman M, et al (2007) A fine tool servo system for global position error compensation for a miniature ultra-precision lathe. International Journal of Machine Tools \& Manufacture 47(7-8):1302-1310.

[19] Zhao D, Bi Y, Ke Y (2017) An efficient error compensation method for coordinated CNC five-axis machine tools. International Journal of Machine Tools \& Manufacture 12(3):105-115.

[20] Wan A, Song L, Xu J , et al (2018) Calibration and compensation of machine tool volumetric error using a laser tracker. International Journal of Machine Tools and Manufacture 12(4):126-133.

[21] Hongyao, Shen, and, et al (2012) On-line Asynchronous Compensation Methods for static/quasi-static error implemented on CNC machine tools. International Journal of Machine Tools and Manufacture 60:14-26.

[22] Huang N, Jin Y, Bi Q , et al (2015) Integrated post-processor for 5-axis machine tools with geometric errors compensation. International Journal of Machine Tools \& Manufacture 94:65-73.

[23] Zha J, Xue F, Chen Y (2017) Straightness error modeling and compensation for gantry type open hydrostatic guideways in grinding machine. International Journal of Machine Tools and Manufacture 112: 1-6.

[24] Anderson-Cook, Christine, M (2009) Response surface methodology; process and product optimization using designed experiments, 3d ed. Scitech Book News, 33(2).

[25] Abbasi B, Mahlooji H (2012) Improving response surface methodology by using artificial neural network and simulated annealing. Expert Systems with Applications 39(3):3461-3468.

[26] Gaing, Zwe-Lee, Lin, et al (2014) Rigorous Design and Optimization of Brushless PM Motor Using Response Surface Methodology with Quantum-Behaved PSO Operator. IEEE Transactions on Magnetics 50(1):1-4 
[27] Anand K, Elangovan S (2017) Optimizing the ultrasonic inserting parameters to achieve maximum pull-Out strength using response surface methodology and genetic algorithm integration technique. Measurement 99:145-154.

[28] Meng F, Dong Q , Wang P, et al (2014) Multiobjective Optimization for the Impeller of Centrifugal Fan Based on Response Surface Methodology with Grey Relational Analysis Method. Advances in Mechanical Engineering 6:614581-614581.

[29] Zheng L, Lu Z, Lun Q, et al (2015) Optimal Design of Multi-DOF Deflection Type PM Motor by Response Surface Methodology. Journal of Electrical Engineering \& Technology 10(3):965-970.

[30] Liu X, Fu W (2016) A Dynamic Dual-Response-Surface Methodology for Optimal Design of a Permanent-magnet Motor Using Finite-element Method. IEEE Transactions on Magnetics 52(3):1-4. 